\author{
FEDERAL RESERVE BANK OF SAN FRANCISCO \\ WORKING PAPER SERIES
}

\title{
Is Asia Decoupling from the United States (Again)?
}

\author{
Sylvain Leduc, \\ Federal Reserve Bank of San Francisco \\ Mark M. Spiegel, \\ Federal Reserve Bank of San Francisco
}

May 2013

Working Paper 2013-10

http://www.frbsf.org/publications/economics/papers/2013/wp2013-10.pdf

The views in this paper are solely the responsibility of the authors and should not be interpreted as reflecting the views of the Federal Reserve Bank of San Francisco or the Board of Governors of the Federal Reserve System. 


\title{
Is Asia Decoupling from the United States (Again)?
}

\author{
Sylvain Leduc \\ and \\ Mark M. Spiegel $^{1}$ \\ May 2, 2013
}

\begin{abstract}
The recovery from the recent global financial crisis exhibited a decline in the synchronization of Asian output with the rest of the world. However, a simple model based on output gaps demonstrates that the decline in business cycle synchronization during the recovery from the global financial crisis was exceptionally steep by historical standards. We posit two potential reasons for this exceptionally steep decline: First, financial markets during this recovery improved from particularly distressed conditions relative to previous downturns. Second, monetary policy during the recovery from the crisis was constrained in western economies by the zero bound, but less so in Asia. To test these potential explanations, we examine the implications of an increase in corporate bond spreads similar to that which took place during the recent European financial crisis in a 3-region open-economy DSGE model. Our results confirm that global business cycle synchronization is reduced when zero-bound constraints across the world differ. However, we find that the impact of reduced financial contagion actually goes modestly against our predictions.
\end{abstract}

J.E.L. Classification Numbers: E32, F41, F44, F62

Keywords: business cycle synchronization, output gap, financial contagion, zero-bound, Asia

\footnotetext{
${ }^{1}$ Federal Reserve Bank of San Francisco, sylvain.leduc@sf.frb.org, and mark.spiegel@sf.frb.org. Israel Malkin provided excellent research assistance. The views in this paper are our own and not necessarily those of the Federal Reserve Bank of San Francisco or the Board of Governors.
} 


\section{Introduction}

During the initial stages of the 2008 global financial crisis, a number of studies asked whether or not the Asian region had "decoupled" from the United States sufficiently to allow it to weather the downward shocks the region was expected to suffer from the decreased US demand for its exports as that nation fell into recession [e.g. Park and Shin (2009)]. Over time, however, the depth of the crisis demonstrated that a sufficiently large adverse shock to demand from the rest of the world could also draw Asia into recession.

For example, consider Figure 1, which depicts annual GDP growth for three Asian series as well as the United States and Europe. We divide Asia into the largest two economies, China and Japan, and the rest of the region which is proxied here by a weighted average of a number of other leading Asian economies. ${ }^{2}$ Gray areas represent the NBER "recession bars" for the United States during the period. The co-movements between all of these Asian groups and their US and European counterparts is readily apparent, particularly for the downturn in all series during the recent global financial crisis.

The notion that business cycle correlations are related to cyclical conditions has been discussed in the literature. Gregory, et al (1997) find that the relative importance of global shocks in individual countries' business cycles varies over time. Bordo and Heibling (2004) and Yetman (2011a) find strong correlations across business cycles during recessions. Kose, et al (2013) and Lam and Yetman (2013) also find that business cycle correlations are also related to macroeconomic volatility.

Also apparent is that the Asian experience during the recent recession was heterogeneous. Japan suffered the worst declines among the 107 country sample for the crisis period studied by Rose and Spiegel (2011), while growth among both China and the emerging Asia group held up relatively well.

\footnotetext{
2 "Europe" contains the 27 country European Union group from Eurostat. "Asia" includes Hong Kong, Korea, Indonesia, Malaysia, the Philippines, Singapore, and Thailand.
} 
China's experience was particularly notable. Chinese real GDP growth only declined from $14.2 \%$ in 2007 to $9.6 \%$ in 2008 , and quickly recovered to $10.3 \%$ by 2010 . The robustness of China's economy was somewhat surprising, given the country's openness and the steep decline in exports from Asia experienced during the crisis. However, the Chinese government was able to encourage its financial sector to engage in an unprecedented credit expansion, which maintained high growth in domestic output.

The literature cited above would suggest that the recovery from the global financial crisis would bring with it a renewed decline in synchronization. This has led to renewed interest in the prospects for Asian decoupling, based in part on growing integration within the Asian region itself [e.g. He and Liao (2012)]. Our results below confirm that bilateral business cycle correlations between the United States (US), the European Union (EU), and the "rest of the world," (ROW) have universally declined vis-à-vis China, Japan, and the "rest of Asia."

However, our results suggest that the recent decline in business cycle correlations has been exceptionally steep relative to historical patterns. We make this assessment by estimating the relationship between the positions of the US and Asian countries in the business cycle and their business cycle correlations. We examine correlations based on a two-year trailing window. We evaluate a country's business cycle position in two ways: Based on its estimated output gap and by its measured unemployment gap, both using OECD data.

Regression results for both measures of cyclical positions are similar (with the expected opposite coefficient sign estimates). We find that correlations are universally sensitive to the US output gap, with stronger correlations holding when the absolute value of the US output gap increases. This is in keeping with much of the cross-country correlation literature. Results for the Asian partner country 
tend to enter positively, although generally with smaller estimated coefficient values and mixed statistical significance.

We then use both the output gap and unemployment gap specifications to estimate a truncated sample, looking at data from 1999Q1 to 2010Q3, and then using the estimated values to predict output gaps out of sample over the period from 2010Q4 to 2012Q3. We find that the realized values of correlations of the United States and Asian business cycles tend to have declined more rapidly during the recent recovery from the global financial crisis than would be predicted by the declines in their respective output gaps. As such, it appears that a portion of the recent decline in US-Asian business cycle correlations is not simply attributable to cyclical declines in correlations comparable to what is commonly observed during economic recoveries. Instead, this extra decline may be attributable to a continuation in the long-term decoupling of the Asian economies from the rest of the world.

However, an alternative reason for the steeper decline this time out may be the nature of the preceding crisis from which both the US and Asia were emerging. Unlike other recessions in our relatively short data set, this recession and the subsequent recovery included substantive disruptions to global financial markets, particularly during the recent crisis in the euro area. It seems plausible that seizing up of financial markets may increase business cycle correlations, as contagion from one financial market to another may increase co-movements, particularly during recessions.

In addition, the recent recovery took place while monetary policy in Western economies were constrained by the zero bound, as interest rates outside of Asia were close to zero and allowed little leeway for further easing. These economies did pursue unconventional monetary easing, for example through "operation twist" and quantitative easing efforts by the Federal Reserve. However, while studies suggest that these unconventional policies have had some easing impact [e.g. Swanson (2011) 
and D'Amico and King (2013)], there can be no doubt that there was greater scope for countercyclical monetary policy in Asia than in the West during this period.

To investigate the potential of these channels to explain the notably steep decline in business cycle synchronization that appears to have emerged subsequent to the crisis, we need to assess how the global economy might have fared under the counter-factual situations where financial contagion remained as strong as it had been during the global crisis and the U.S. and European monetary policies were not at the zero bound constraint. We therefore turn to the predictions of a 3-block DSGE model used by the Federal Reserve, known as SIGMA. This model is calibrated to the economies of the US, Europe, and a third block which we refer to as "Asia," but which in fact also includes a number of emerging economies. Still, the bulk of output in this block is accounted for by Asian economies.

We examine the implications of financial contagion and the zero bound constraint on monetary policy for output correlations during the recovery period via a simulation of the effects of the financial crisis in Europe. We allow European corporate bond spreads to increase by five percent, the "trough-topeak" increase in spreads observed in Europe during its financial crisis. We first evaluate the impulse responses of this shock without financial contagion, i.e. where shocks to corporate spreads in Europe are not correlated with shocks to corporate spreads in Asia and the United States, and with monetary policy in the United States and the "Europe block" constrained by zero lower bound for interest rates.

Our results demonstrate that the increase in corporate spreads leads to a sharp drop in European GDP, which weighs on economic activity in both the US and Asia. However, we then entertain alternative intensities of financial contagion by calculating the peak effect of the European shock at different contagion intensities. We find that the magnitude of the downturn that follows the financial shock is sensitive to the degree of financial contagion; increased financial contagion implies that both the US and the Asia block decline more in response to the European shock. Given the finding in the 
literature that business cycle correlations increase during downturns, we would expect this to imply that financial contagion raises business cycle synchronization.

We then examine the implications of the zero-bound monetary policy constraint by running the same simulation with the zero bound constraint removed for the US and European blocks. This allows the central banks of these blocks to respond to the European financial shock. In principle, the impact of the zero-bound constraint on the synchronization of business cycles is ambiguous. On one hand, the inability of the US and European monetary authorities to pursue further countercyclical monetary policies would be expected to exacerbate the downturns in all three blocks, increasing business cycle synchronization. However, the pursuit of counter-cyclical policy by the Asian bloc alone should result in mitigation of downturns in that region relative to those suffered in the West, reducing the synchronization of Asian and Western output.

Our results demonstrate that incorporation of the zero bound constraint faced by the US and Europe, but not by Asia, is associated with lower business cycle correlations between the US and Asia. In contrast to our expectations, however, we observe a modest decline in correlation when we move from no contagion to a specification of high financial contagion. This is explained below by the fact that US sensitivity to the European interest rate shock is larger than that of the Asia block. Overall, our results suggest that the dominant channel above is the impact of the heterogeneous zero bound constraints on European and US monetary policies.

The remainder of this paper is separated into 5 sections. The following section reviews the literature on synchronization of business cycles. Section 3 reviews the evidence concerning business cycle correlations between Asia and the United States. Section 4 introduces the SIGMA model and examines the sensitivity of US output to Asian shocks with and without contagion in Asian and US financial markets. Lastly, section 5 concludes. 


\section{Literature on decoupling and the synchronization of Asian business cycles}

The decoupling literature following the crisis primarily centered on the question of the capability of Asia to endure in the face of a steep Western output decline [e.g. Kim, et al (2011)]. By and large the evidenced was mixed: Asia as a region experienced softer declines than, for example, Latin America and Eastern Europe, but even inclusive of the Chinese the impact on Asia was apparent. With the recovery, the decoupling question shifted from the ability of Asia to sustain growth in the face of adverse shocks from the West to that of whether the West can benefit from the superior performances by Asian nations during the recovery, or indeed, whether Asian economies can "substitute" for the United States as the driver of the global economy [e.g. Yetman (2011b)].

All discussions of increased interdependence of the Asian economies with the rest of world begin with the dramatic increased in Asian trade integration with the global economy. There can be no doubt that the trade volumes of Asian economies have increased relative to their GDP. From 2000 through 2010, the volume of international trade from Asia as a share of its GDP has increased from 30 to 42 percent. This increased trade integration between Asia and the rest of the world has been validated using disaggregated data by Pula and Peltonen (2011).

As has been well-documented in the literature, however, increased trade integration does not necessarily suggest that countries will have more synchronous business cycles. While increased trade may facilitate the international transmission of aggregate demand shocks in individual countries, as well as global common shocks, leading to increased cycle synchronization [e.g. Frankel and Rose (1998)], it can also lead to reduced synchronization. Economies are likely to respond to increased trading opportunities by increasing their degree of product specialization, leading to greater differences in output bundles, which may reduce synchronization [e.g. Kose and Yi (2002)]. Even through this channel, 
however, there is a possibility of ambiguity as specialization that leads to increased vertical integration can actually raise synchronization [Imbs (2004)].

There can also be no doubt that Asia as a region is becoming more financially open as well. Since 2001, total holdings of US and European assets by Asia as a region, excluding China, as a share of GDP grew by close to 50 percent. $^{3}$ Theory is also ambiguous about the predicted impact of financial openness on business cycle synchronization. By facilitating the hedging of consumption risk, financial openness may also encourage countries to become more specialized, leaving their output responses more different in the wake of sector-specific shocks. However, increased financial linkages may lead to increased contagion, raising the synchronization of aggregate demand across countries, and thereby that of business cycles as well [e.g. Claessens and Forbes (2001)].

The empirical results for both trade and financial linkages are also ambiguous. Most studies, such as Frankel and Rose (1998) and Kose and Yi (2006) find trade linkages lead to increased business cycle synchronization. However, Rose and Spiegel (2010) find no evidence that exposure to the United had adverse effects on national performances during the global financial crisis. If anything, they find that trade exposure to the US was actually beneficial during the crisis, despite the fact the crisis originated and was centered in the United States.

On the financial side, the evidence concerning the impact of financial integration on business cycle synchronization appears to be even more ambiguous. Imbs (2006) finds that correlations in GDP fluctuations increase with financial integration. ${ }^{4}$ However, Kalemli-Ozcan, et al (2009), find that increased financial integration measured by banking exposure reduces business cycle synchronization.

\footnotetext{
${ }^{3}$ The share increased from $21 \%$ in 2001 to $32 \%$ in 2009.

${ }^{4}$ Other studies, such as Hwang, et al (2013) also find that financial openness is also associated with increased output volatility.
} 
Rose and Spiegel (2010) find that financial exposure to the United States also had a positive impact of national performances during the global financial crisis.

Of course, one issue is that globalization was encouraging both increased trade and financial integration at largely the same time. As a result, it is difficult to identify which of the two features is driving business cycle synchronization, and some studies merely look at the change in business cycle synchronization over time, without trying to identify the channels through which changes in synchronization occurred. Heathcoate and Perri (2004) find that correlations between the United States and an aggregate of other developed economies was lower in the latter portion of their data, suggesting that synchronization among this group of nations had diminished. However, Kose, et al (2008) use a dynamic factor model and find that find that a global factor explains a large share of volatility in their later sample, and view this as evidence of increased global synchronization over time.

A related, but distinct question is whether these economies are becoming more integrated with the world outside of Asia, or with each other? This latter question confronts the issue of "decoupling" in Asia. Those suggesting Asian decoupling claim that the region is becoming more interdependent, rather than more integrated with the world as a whole. Using a dynamic factor model, Hirata, et al (2013), find evidence of an increase in the explanatory power of regional factors in explaining output, but a global factor's influence is found to have actually declined over the same period. They argue that recent globalization has facilitated regional business cycle synchronization rather than global synchronization.

Interest in the decoupling question increased dramatically when it became clear that the United States was going to suffer a protracted recession, and that there would be some drag from that recession on other developed economies. Initially, the intensity of contagion from the US downturn was underestimated, but policy makers in Asia were particularly interested in knowing whether their reduced dependence on these economies would be sufficient for them to avoid a downturn as well. As 
we now know, this would not be the case, as the downturn became the deepest one since the Great Depression. However, many of the arguments used to motivate the existence of Asian "decoupling" proved to be true, even though Asian economies always exhibited some interdependence with the rest of the global economy.

One argument stressed in the literature [e.g. Kim, et al (2011)] was that a portion of what appeared to be decoupling in the data was in fact the manifestations of the increased size and influence of Asian economies. Asia as a region grew 4.3\% annualized from the end of the Asian financial crisis in 1998 to 2012. Moreover, Asia ex Japan grew by 7.8\%. At the end of this period, the Asian economies represented roughly 24 percent of World GDP. Inevitably, the interdependencies between Asia and the West now reflected shocks running in both directions, raising the possibility of positive spillovers from the Asian economies to the rest of the world.

This possibility is directly raised by Kim, et al (2011), who argue that Emerging Asia is indeed "recoupling" with the developed G7 economies in a manner that allows for Asian growth to have substantive positive spillovers on the performances of those economies. ${ }^{5}$ Using a panel vector autoregression methodology, they find that the impact of G7 shocks on Asian economies increased substantially subsequent to the Asian financial crisis, supporting earlier evidence that Asian economies were becoming more globalized and increasingly sensitive to global shocks.

However, they also found a substantial impact of East Asian shocks on G7 output. They find that the contribution of East Asian shocks in G7 output fluctuations increased from 20 percent in the 1990s to 50 percent in the previous decade. Part of this increase in the influence of the East Asian region was attributable to discrepancies in the average size of shocks (with East Asia having larger shocks on

\footnotetext{
${ }^{5}$ See Kim, et al (2011) for the list of nine emerging Asian economies studied. The G7 countries include Canada, France, Germany, Italy, Japan, United Kingdom and the United States.
} 
average than the G7), but even after adjusting for this discrepancy they find that East Asian shocks are about as influential on G7 output fluctuations as shocks running in the opposite direction.

\section{Asian business cycle synchronization after the crisis}

Most of the studies mentioned above, with the notable exception of Harati, et al (2011), look at samples that end prior to the global financial crisis. As discussed in the introduction, there was substantive discussion about the possibility that Asia was decoupling going into the crisis. If anything, one would think that Asia would be further isolated from the rest of the world subsequent to the crisis, as intra-regional trade in Asia continued to develop during recent years, and as Asia took off relatively robustly after the crisis while recoveries in Europe and the United States were sluggish.

We first examine the correlations in output fluctuations between China, Japan and our Asia-exChina and Japan groups, and the United States and Europe. ${ }^{6}$ We then examine the correlations between these Asian groups and the "rest of the world" (ROW), defined as global GDP minus US, European, and our measured Asian GDP. Our sample goes from the Asian financial crisis to the present. We have quarterly data from the $1^{\text {st }}$ quarter of 1997 through the $3^{\text {rd }}$ quarter of 2012 for all of our series except the ROW series, which is constructed using the global output data that is only available from the $1^{\text {st }}$ quarter of 1998. Our data comes from standard sources. Data on global, US, Japan, and China real GDP is obtained from Bloomberg, while real GDP data for Europe obtained from eurostat and data for the rest of Asia is obtained from the IMF's International Financial Statistics. We deseasonalize the data and detrend it using the Hodrik-Prescott filter, and then calculate correlations in changes in real GDP for each quarter based on an eight quarter sample including that quarter and seven lags.

\footnotetext{
${ }^{6}$ The Asia ex China and Japan group includes Hong Kong, Indonesia, Korea, Malaysia, Philippines, Singapore, and Thailand, while the Europe group includes the eurostat 27 country Europe group.
} 
Correlations between the three Asian series and the United States are shown in Figure 2. It can be seen that correlations between the US and all three Asian series increased during the two US recessions over the previous decade, with a notable increase during the global financial crisis. This illustrates that a sufficiently large western shock would still influence the Asian economies. However, between these two recessions we observe a notable decline in US synchronization with Japan, China, and our emerging Asia aggregate. This correlation actually dips negative for China and the emerging Asia subgroup at the middle of the decade. This negative period probably motivated much of the discussion of Asian decoupling prior to the global financial crisis.

We examine the movements in these correlations, as well as those with the other global subgroups, by separating our sample into two time periods: One from the first quarter subsequent to the 2001 recession (Q1 2002-Q3 2007) to the last quarter prior to the global financial crisis, and one beginning in with the first quarter following that recent global recession (Q3 2009-Q3 2012) until the end of our sample. We then calculate business cycle correlations of the three Asian series with the three other world regions, as well as correlations with the rest of Asia.

The results from this exercise are shown in Table 1. One immediate implication of the analysis is that Japan appears to be moving on its own, as its correlation with China, Asia ex china and Japan, the United States, the European Union, and the rest of the world group (ROW) have all declined. These numbers indicate that the Japanese economy truly moved in a different pattern than the rest of the global economy subsequent to the global financial crisis. Of course, Japan suffered major disruptions during this period, particularly this year due to shocks associated with the devastating Tohoku earthquake. As such, it may be premature to make any generalizations about the synchronicity of the Japanese business cycle with those of its neighbors or with the rest of the global economy. Still, the 
Japanese experience appears to be notably different from the rest of the world both before and after this event.

Turning to China, our data show that Chinese business cycle synchronization with Asia ex China and Japan has also decreased dramatically since the global financial crisis. This conflicts with studies, such as Harati, et al (2011) who claim that Asia is becoming more regionally integrated. Our longer time series reveals that with the recovery from the crisis, China is moving away from the rest of Asia as well. However, synchronization with the United States and the European Union are much higher subsequent to the crisis, while correlation with the rest of the world has declined. The data therefore suggest that rather than decoupling with the global economy, China's economy is becoming more integrated with both of its primary Western trading partners, while it seems to be moving away from both the rest of Asia (net of Japan) and the remaining global economy.

Lastly, we consider the Asia ex China and Japan group. As discussed above, this group is becoming less synchronized with its major regional trading partners, as business cycle correlations with both China and Japan have decreased subsequent to the crisis. However, our data suggest that business cycle correlations have also decreased substantially between Asia ex China and the ROW subsequent to the crisis.

Overall, our results disagree with much of the literature that suggests that Asia is uniformly becoming ever more integrated with itself and less so with the rest of the world. The region is clearly pulling back from the high levels of within-region integration it displayed immediately prior to and including the crisis period, when much of the recent decoupling literature was written. Instead, it appears that after the crisis China is becoming more integrated with the United States and Europe while the rest of Asia becomes less synchronized with the West. 
Correlations with the rest of the world have declined among all of the Asian groups in our sample. In part, this reflects the fact that most Asian nations are importers of many of the primary products, including commodities, sold by this region. Still, this was also the case prior to the crisis. With the caveat that this is a quite heterogeneous group, including Russia, Australia and Oceana, Latin America, Canada, as well as all of Africa, so that generalizations should be made with caution, our results do not appear to support the contention that rapid growth in Asia, particularly in China, would perform as a locomotive for the ROW group due to Asia's hunger for commodities.

\section{Movements in business cycle correlations due to output gaps.}

In this section, we parameterize the relationship between US-Asian business cycle relationships and the regions' positions in the business cycle. We measure business cycle positions through two independent output gap measures. First, we use the direct measure of the output gap as reported by the OECD. Second, as a robustness check, we also examine the implications of business cycle positions as proxied by measured unemployment gaps, also as reported through OECD data. This latter measure is intended as a robustness check, as it is only available for Japan and Korea among Asian nations.

We relate business cycle correlations to observed positions in the business cycle according to the following specification:

$$
\rho_{U S, i, t}=\alpha+\beta_{i} Y G A P_{i, t}+\beta_{U S} Y G A P_{U S, t}+\varepsilon_{t}
$$

where $\rho_{U S, i, t}$ represents the correlation between the United States and country $i$ at time $t, Y G A P_{i, t}$ represents the output gap of country $i$ at time $t$, measured in two different ways discussed below, $Y G A P_{U S, t}$ represents the output gap of country i at time t, also measured in two different ways, and $\varepsilon_{i t}$ is an error term assumed to be i.i.d. 
We measure the output gap in two ways. First, we consider the actual output gap measure reported by the OECD Stats library. ${ }^{7}$ Second, as a robustness check, we also use the unemployment gap, also from OECD data. Among Asian countries, this latter measure is only available for Japan and Korea, which we also group as a smaller "Asia" group for the unemployment gap regression results.

Our results are shown in Tables 2 and 3. We consider four groups of Asian countries that we pair with the United States to examine business cycle correlations, with Asian countries weighted by country size. Our four groups include China, Japan, a "Rest of Asia" group, which includes Indonesia and Korea, and an "Asia" group, which includes the Rest of Asia group plus China and Japan. ${ }^{8}$

It can be seen that the US output gap (which enters as a larger negative number when the output gap increases) enters with its expected negative sign at statistically significant levels. This is in keeping with the literature that suggests that business cycle correlations decline with economic activity. However, we obtain a positive and statistically significant coefficient estimate for the partner's output gap for both the Japan and the Rest of Asia groups. Our measured R-squares are fairly good for our relatively parsimonious specification, as high as 0.46 for the China group and as low as 0.28 for the Rest of Asia.

The positive coefficient we obtain on the partner's measured output gap is counter to the notion that output gaps are necessarily decreasing in business cycle activity. One answer to this discrepancy between the signs on the two measured output gaps may be that the recessions shown to coincide with increased business cycle correlations may also coincide with global downturns, proxied well in many cases by US output. In other words, the US output gap may be more highly correlated with the output gap for the world as a whole than that of its Asian counterpart.

\footnotetext{
${ }^{7}$ See stats.OECD.org.

${ }^{8}$ Comparable output gap data was unavailable for Malaysia, the Philippines, Singapore, and Thailand.
} 
To check the robustness of this result, we also examine the implications of output gap movements as measured by the unemployment gap. This measure is available for only advanced economies, so our Asian countries are limited to Japan and Korea. We also examine the sum of these economies as a "Japan+Korea" group. We subject these partners to the same specification, examining the implications of changes in unemployment gaps on business cycle correlations.

Our results are shown in Table 3. In this case, an increase in unemployment is measured as positive movements in the unemployment gap. As such, these results mirror those that we obtained for the output gaps. We obtain a positive coefficient estimate on the US unemployment gap for all specifications, significantly so for the Japan+Korea and Japan samples. As before, however, we also get a surprising negative coefficient estimate on the Asian partner's unemployment gap, suggesting that a deeper downturn in Asia actually reduces business cycle correlations between the US and Asia.

Overall, our results suggest that the relationship between output levels and business cycle correlations may be dependent on which partners' output levels one is considering. Moreover, it may also indicate that global downturns are driving the observed relationships between the intensity of business cycle correlations and output levels. However, in all cases we obtain substantive explanatory power for measures of output gaps in the time series variations of business cycle correlations.

We therefore use our estimated models to predict business cycle correlations out of sample. This will allow us to gauge whether the observed downturn in the recent recovery was exceptional relative to historical data or not. We estimate the model based on data from 1997Q1 to 2010Q3, then use estimated coefficient estimates with realized data from 2010Q4 to 2012Q3. Results for the in-sample regressions with output gap data are shown in Appendix Table 1, and those for regressions using unemployment gap data are shown in Table 2. 
Our results for the Asia group using output gap measurements, and for the Japan+Korea group using unemployment gaps, are displayed in Figure 3. It can be seen that the realized decline in business cycle correlations is larger than that which would be predicted our fitted model for both output gap measures. Our output gap model predicts a correlation between the US and our Asia group of 0.90, while the realized correlation is only 0.57 . Similarly, our unemployment gap model predicts a correlation between the US and our Japan+Korea group of 0.87 at the end of our forecast period, while the realized correlation is only 0.45 . The results for individual country correlations are similar, as shown in Table 4.

We therefore conclude that the decline in business cycle correlations between the US and Asia subsequent to the recent crisis has been steeper than would be predicted by past business cycle movements. In the next section, we consider two potential explanations for this pattern.

\section{Financial Shocks in An Open-Economy DSGE Model}

\section{a. Two explanations for the steep decline in business cycle correlations between the US and Asia}

One possible explanation for the steeper decline in business cycle correlation relative to the predictions of past business cycle movements is that the Great Recession involved the seizing of financial markets in the United States. Through financial contagion, this shock was rapidly transmitted around the world, and led to the worst downturn since the Great Depression. However, as the global economy recovered, financial conditions were quickly restored to normal activity in terms of trading volumes, albeit at heightened spreads reflecting that risk remained elevated. Financial contagion may therefore have been a force for increased business cycle correlation during the crisis, and its mitigation may have encouraged a decline in these correlations. Because of the exceptional degree of financial turmoil in the recent crisis, the decline in financial seizing was likely exceptional for an economic recovery as well. 
Alternatively, during the global financial crisis monetary policy in the United States responded by quickly lowering the policy rate to effectively zero, its lower limit, and then by conducting large-scale asset purchases, as well as by providing more forward guidance regarding the future path of monetary policy. The European Central Bank (ECB) also lowered its policy rate rapidly in the wake of the crisis, bringing it to one percent by mid-2009. The ECB also use forward guidance to calm and guide financial markets stating that it is ready to do whatever it takes to defend the euro. However, with the notable exception of Japan, Asian economies were relatively unconstrained by the zero interest rate bound. This difference in the capacity to pursue conventional counter-cyclical monetary policy between the Asian and Western economies may also have contributed to the steep declines in observed business cycle correlations subsequent to the global financial crisis.

We therefore evaluate the merits of these two potential channels in terms of their importance in influencing business cycle correlations during the recovery from the Great Recession. Of course, during this period the European debt crisis provided another setback, raising sovereign and corporate yields in many European countries, and slowing growth in Europe, the United States, and Asian economies. We examine how much the two channels identified above - reductions in financial contagion and heterogeneous constraint by the zero bound on counter-cyclical monetary policy -- contributed to lowering business-cycle correlations during the recovery period by comparing the performance of the global economy during this "second-shock" period.

\section{b. An open-economy DSGE application using the SIGMA model}

To examine the impact of a financial shock in Europe and its effect on the U.S. and Asian economies, we use the SIGMA open-economy DSGE model developed at the Board of Governors of the Federal Reserve System by Chris Erceg, Luca Guerrieri, and Chris Gust (see, Erceg, Guerrieri, and Gust (2006) and Bodenstein, Guerrieri, and Gust (2010) for a detailed description of the technical features of the model). 
The version of the SIGMA model that we use is composed of three countries (areas), calibrated to represent the United States, Europe, and the rest of the world, which we refer to as Asia. ${ }^{9}$

One important aspect of the SIGMA model for our purposes is that it includes a financial accelerator, which allows us to consider the effects of a financial crisis in Europe. Moreover, an additional feature of the SIGMA model that allows us to better capture the effects of the financial shock in Europe and its transmission around the world is the fact that it explicitly allows for the presence of a zero bound on nominal interest rates. As we argued above, the zero lower bound constraint on the policy rate was a central feature of the U.S. economy and also to a large extent the euro area at the time that the European debt crisis occurred.

In addition, the SIGMA model includes a competitive composite consumption goods sector, which produces consumption goods using nonoil final goods and oil services in a CES production function. ${ }^{10}$ The nonoil final goods are themselves produced using imported and domestic intermediate tradable differentiated products. These intermediate inputs are sold by a continuum of monopolistically competitive firms. There are nominal rigidities in the model: firms only reset prices in some periods, otherwise their prices increase with lagged inflation. Wages also follow similar rigidities. Firms practice local currency pricing, and price discriminate between regions due to the presence of non-constant demand elasticities as in Gust, Leduc, and Vigfusson (2010).

The model also includes a fraction of non-optimizing, hand-to-mouth households as well as real rigidities: Convex adjustment costs are assumed on investment and imports, while households are subject to habit persistence in consumption. Domestic financial markets are assumed to be complete,

\footnotetext{
${ }^{9}$ Only slightly over $60 \%$ percent of output in this aggregate rest of the world is truly Asian.

${ }^{10}$ Since the SIGMA model is used in policy analysis, we are precluded from releasing the details of its specification, or the values used in our calibration analysis.
} 
but international ones are not, as only a pure discount bond in each country can be traded internationally.

Physical capital is produced by a competitive group of capital producers. Physical capital is purchased by risk-neutral entrepreneurs who transform it into capital services using a stochastic technology subject to idiosyncratic productivity shocks. Purchases of physical capital are financed from entrepreneurs' own wealth or borrowed from perfectly competitive banks. Depending on the realization of the idiosyncratic productivity shock, borrowers may decide to default on their debt. The presence of costly external finance implies that the entrepreneur pays a premium over the risk-free rate to borrow funds from banks. This premium rises with the size of the debt relative to the entrepreneur's net worth, reflecting the increase in expected default costs.

When not at the zero lower bound on nominal interest rates, monetary policy in each country follows an interest rate rule based on deviations from the interest rate target and the output gap.

We first examine the benchmark case of a financial crisis in Europe without financial contagion and with monetary policy in the European and US blocks constrained by the zero lower bound. We model the shock associated with the European crisis through an increase in European corporate spreads. ${ }^{11}$ The exercise consists in increasing corporate bond spreads in Europe by five percent, reflecting the "through-to-peak" movements in high-yield European corporate bond spreads observed during the that debt crisis. We model the lack of financial contagion through the assumption that that the financial shock to Europe does not trigger financial contagion to U.S. and Asian financial markets.

We also assume that the policy rates in the United States and Europe are at the zero lower bound at the time of the financial shock in Europe, reflecting previous negative shocks to aggregate

${ }^{11}$ Corporate firms borrowing rate can differ from that of the government due to the presence of a "risk" shock, i.e., disturbances to the bond pricing equations. 
demand. In contrast, the policy rate in Asia remains positive. This was also true at the time of the European crisis. ${ }^{12}$ Once these shocks dissipate and the economies start to recover, monetary policy in Europe and the United States move away from the zero lower bound and the policy rates in the two areas are determined by the interest-rate rules. We assume that the European financial crisis occurs two years after the negative shocks to aggregate demand associated with the Great Recession.

The effects of the increase in Europe's corporate spreads are depicted in Figures 5 and 6, assuming that the financial shock to Europe does not trigger financial contagion to U.S. and Asian financial markets. Figure 5 shows the movements in the policy rates in Europe and the United States, as well as the bilateral U.S. exchange rate against Europe and Asia, respectively. It shows that following the negative shocks to aggregate demand associated with the global financial crisis, the policy rates in Europe and the United States are lowered to zero within two years. Thus, when the European financial crisis happens (at quarter eight in the figure), monetary policy in Europe and the United States are already at the zero lower bound and cannot offset the negative impact on growth and inflation via declines in the policy rates. The financial crisis triggers an outflow of capital from Europe, which raises the value of the dollar.

As shown in Figure 6, the effect of the increase in European corporate spreads triggers a large drop in Europe's GDP, which falls by about 6 percent. In turn, the fall in aggregate demand in Europe leads to declines in economic activity in the United States and Asia, as these regions exports less to Europe, though the magnitudes of the downturns are much smaller. U.S. and Asian corporate spreads also rise somewhat, reflecting the mild recessions in the two areas.

\footnotetext{
${ }^{12}$ The Asian positive policy rate masks a heterogeneous group of countries in this block, including, notably, Japan, whose central bank was constrained by the zero bound, China, whose monetary policies were better characterized as changes in financial conditions through manipulation of lending levels.
} 
Clearly, the impact of a financial shock originating in Europe on the economies of the United States and Asia will depend on the extent of financial contagion. We examine this issue in Figure 7, which reports the financial shock's peak effect on GDP in Europe, the United States, and Asia, assuming different degrees of correlation between the shocks to corporate spreads around the world. Figure 7 demonstrates that the declines in GDP in Asia and the United States stemming from the corporate bond spread shock in Europe are indeed sensitive to the degree of financial contagion between Europe and the rest of the world. One might therefore expect that a decline in corporate bond spreads would reduce business cycle correlations, as a downturn in Europe would lead to a smaller downturn in both the United States and Asia.

Finally, we assess the importance of the binding zero lower bound in Europe and the United States for the magnitude of output declines in response to the increase in European corporate spreads. To do so, we simulate our model and examine the responses of the three regions, abstracting from the zero lower bound that otherwise constrains monetary policy in Europe and the United States. As in Figure 7, Figure 8 reports the peak output response in Europe, the United States, and Asia under different degree of financial contagion across world financial markets, but with the assumption that the zero lower bound is not binding in Europe or the United States. Compared to Figure 7, the peak European and U.S. output responses in Figure 8 are substantially muted, reflecting the ability of monetary policy to offset part of the effect of the financial shock on economic activity. For a high degree of financial contagion, the peak output declines in Europe and the United States are nearly halved.

Comparing Figures 7 and 8, it is apparent that the magnitude of the output declines is more similar across the three regions when monetary policies in Europe and the United States are unconstrained by the zero lower bound (Figure 7), particularly for moderate to high degree of financial contagion. Intuitively, when monetary policy in the United States and Europe are constrained, but 
monetary policy in Asia can be eased to offset the impact of the financial shock, the resulting correlation in output between the United States and Asia is reduced.

Our results therefore suggest that output correlations would be highest with international financial contagion and with none of the groups' monetary policies constrained by the zero bound. To evaluate this, we examine the output correlations between the US and Asia blocks with and without financial contagion and when the zero bound monetary policy constraint on the United States and Europe is imposed or not. The results are shown in Table $5 .{ }^{13}$

The results for the zero bound constraint shows that there is a decline in output correlations with the introduction of the zero bound, either with or without financial contagion. There is a particularly sharp drop in output correlations when under financial contagion when the zero bound on Europe and the US is introduced, with the correlations falling from 0.980 to 0.867 . This reflects the fact that U.S. monetary policy cannot offset the negative output effect arising from financial contagion owing to the zero bound constraint, while the countries in the Asian block can (and do) move to offset the negative shock.

However, we obtain surprising distinctions depending on the presence or absence of financial contagion, for a given assumption regarding the zero lower bound. Table 5 indicates that with or without the zero lower bound imposed the introduction of financial contagion reduces somewhat, rather than raises, output correlations between the US and Asia after the European shock. Our conjecture was that holding all else equal less contagion would imply a shallower downturn and hence less correlated output paths for the US and Europe. However, the same increase in spreads is shown in Figures 7 and 8 to result in a sharper output decline in the US block than in the Asian block, opening the

\footnotetext{
${ }^{13}$ Our results also match the findings in Kose, et al (2013) that recovery speeds are likely to be sensitive to interest rate levels.
} 
possibility that the output correlation in the wake of increased financial contagion could fall, rather than rise.

Indeed, this seems to be what has happened in or simulation. Intuitively, while increased financial contagion leads to a sharper drop in both blocks, the drop is even steeper in the US than it is in Asia, so much so that the correlation in output declines rather than increases.

Overall, then, our results appear to favor the explanation that the exceptionally steep declines observed in business cycle correlations between the US and Asia during the recovery from the recent recession are attributable to differences in capacity for counter-cyclical monetary policy when the European crisis hit. The U.S. policy rate was already at zero when the European debt crisis occurred, whereas this wasn't the case in Asia. Previous business-cycle movements would fail to account for this pattern, given that U.S. monetary policy remained unconstrained until the end of 2008. In contrast, it appears that if anything, the return of financial markets to normalcy during the recovery may have acted to increase output correlations between the US and Asia, as the US economy is much more sensitive to financial contagion in our model than the Asian block.

\section{Conclusion}

In this paper, we demonstrate that the decline in business cycle correlations observed between the United States and Asian economies has been steeper during the recovery from the global financial crisis than it has been in past recoveries. We then offer two potential explanations for this discrepancy: First, as output correlations tend to increase in downturns, a possibility is that the recovery from the seizing up of financial markets during the global financial crisis, which exhibited an unprecedented level of financial turmoil relative to the rest of our sample, might lead to a decrease in output correlations. Alternatively, the fact that monetary policy was constrained by the zero lower bound in the United 
States while monetary policy in much of Asia was unconstrained might lead to heterogeneity in monetary policy responses to the European crisis, and thereby decreased business cycle correlations.

We turned to the SIGMA DSGE model to answer this issue. We modeled the European crisis, which hampered the recoveries in much of the world, as a sharp increase in corporate bond spreads and then evaluated the output responses under different assumptions concerning the impact of the zero bound on the pursuit of counter-cyclical monetary policy and the intensity of financial contagion between Europe and the rest of the global economy. Our results favored the zero-bound hypothesis by demonstrating that output correlations were lower with the US and Europe constrained by the zero bound regardless of the intensity of financial contagion posited, but particularly so for the case with relatively high financial contagion.

We acknowledge that the statement that US monetary policy was constrained by the zero bound and the Asian bock was not is a little simplistic. In our modeling approach, we abstracted from the fact that U.S. monetary policymakers have attempted to bypass the constraint imposed by the zero lower bound by relying on unconventional monetary policy tools, such as large-scale asset purchases or greater forward guidance. Yet, the effects from these new policies are still debated. Their benefits may well be second order compared to the loss of the policy rate as the primary tool for conducting monetary policy.

Moreover, the "Asia block" in the SIGMA model represents a very diverse set of countries. Even abstracting from the non-Asian countries in the block, the Asian countries are also in very different positions concerning their capacity to pursue counter cyclical monetary policy. Japan has been close to the zero bound for quite some time. Many of the smaller Asian nations are better characterized as small open economies with exchange rate goals that can conflict with monetary policy agendas. Finally, China pursue monetary policy at least as much through lending guidance as through manipulation of domestic 
interest rates. Examining in more details the responses of monetary policy with Asia and how it may have contributed to the decline in business-cycle correlations during the recovery period should be a fruitful avenue for future research. 


\section{References}

Akin, Cigdem, and M. Ayhan Kose, (2008), "Changing Nature of North-South Linkages: Stylized Facts and Explanations," Journal of Asian Economics, 19(1), 1-28.

Bodenstein, Martin, Luca Guerrieri, and Christopher Gust, (2010), "Oil Shocks and the Zero bound on Nominal Interest Rates," Board of Governors of the Federal Reserve System International Finance Discussion Papers, Number 1009, September.

Bordo. Michael D. and Thomas Heibling, (2004), Have National Business Cycles Become More Synchronized? In Sibert, Horst, ed., Macroeconomic Policies in the World Economy, Springer-Verlag, Berlin, 3-39.

D’Amico, Stefania and Thomas B. King, (2013), "Flow and Stock Effects of Large-Scale Treasury Purchases: Evidence on the Importance of Local Supply," forthcoming, Journal of Financial Economics.

Erceg, Christopher J., Luca Guerrieri, and Christopher Gust, (2005), "Expansionary Fiscal Shocks and the US Trade Deficit," International Finance, 8(3), 363-397.

Erceg, Christopher J., Luca Guerrieri, and Christopher Gust, (2006), "SIGMA: A New Open Economy Model for Policy Analysis," International Journal of Central Banking, March, 1-50.

Frankel, Jeffrey A. and Andrew K. Rose, (1998), "The Endogeneity of the Optimum Currency Area Criteria," Economic Journal, 108, 1009-25.

Gregory, Allan W., Allen C. Head and Jacques Raynauld, (1997), "Measuring World Business Cycles," International Economic Review, 38(3), August, 677-701

He, Dong and Wei Liao, (2012), "Asian Business cycle Synchronization," Pacific Economic Review, 17(1), 106-135.

Heathcoate, Johnathan and Fabrizio Perri, "Financial Globalization and Real Regionalization," Journal of Economic Theory, 119(1), 207-43.

Hirata, Hideaki, M. Ayhan Kose, and Christopher M. Otrok, (2013), "Regionalization vs. Globalization," FRB St. Louis Working Paper 2013-002A, January.

Hwang, Kwang-Myoung, Donghyun Park, and Kwanho Shin, (2013), "Capital Market Openness and Output Volatility," forthcoming, Pacific Economic Review.

Imbs, Jean, (2004), "Trade, Finance, Specialization and Synchronization," Review of Economics and Statistics, 86, 723-734.

Imbs, Jean (2006), "The Real Effects of Financial Integration," Journal of International Economics, 68, 296-324.

Kalemli-Ozcan, Sebnem, Bent E. Sorensen, and Oved Yosha, (2001), "Economic Integration, Industrial Specialization and the Asymmetry of Macroeconomic Fluctuations," Journal of International Economics, $55,107-137$.

Kalemli-Ozcan, Sebnem, Bent E. Sorensen, and Oved Yosha, (2003), "Risk Sharing and Industrial Specialization: Regional and International Evidence," American Economic Review, 93, 903-18. 
Kalemli Ozcan, Sebnem, Elias Papaioannou, and Jose Luis Peydro, (2009), “Financial Regulation, Financial Globalization and the Synchronization of Economic Activity, NBER Working Paper 14887.

Kim, Soyoung, Jong-Wha Lee, and Cyn-Young Park, (2011), "Emerging Asia: Decoupling or Recoupling?," The World Economy, 23-53.

Kose, M. Ayhan, Christopher Otrok, Charles Whiteman, (2008), "Understanding the Evolution of World Business Cycles," Journal of International Economics, 75(1), 110-130.

Kose, M. Ayhan, Prakash Loungani, and Marco E. Terrones, (2013), "From the Global to the National Cycle: An Intricate Liaison," forthcoming, Pacific Economic Review.

Kose, M. Ayhan and Kei-Mu Yi, (2002), "The Trade Co-Movement Problem in International Macroeconomics," Federal Reserve Bank of New York Staff Report No. 155, December.

Kose, M. Ayahn and Kei-Mu Yi, (2006), "Can the Standard International Business Cycle Model Explain the Relation Between Trade and Comovement?", Journal of International Economics, 68, 267-295.

Gust, Christopher, Leduc, Sylvain and Robert J. Vigfusson (2010), "Trade Integration, Competition, and the Decline in Exchange-Rate Pass-Through," Journal of Monetary Economics 57, 309-324.

Park, Yung Chul and Kwanho Shin, (2009), "Economic Integration and Changes in the business Cycle in East Asia: Is the Region Decoupling from the Rest of the World?," Asian Economic Papers, 8(1), 107-140.

Pula, Gabor and Tuomas A. Peltonen, (2011), "Has Emerging Asia Decoupled? An Analysis of Production and Trade Linkages Using the Asian International Input-Output Table," in Y. W. Cheung, V. Kaaker and G. Ma, eds., The Evolving Role of Asia in Global Finance, Frontiers of Economics and Globalization, Volume 9, Chapter 11, 255-286.

Rose, Andrew K. and Mark M. Spiegel, (2010), "Cross-Country Causes and Consequences of the 2008 Crisis: International Linkages and American Exposure," Pacific Economic Review, 15(3), 340-363.

Rose, Andrew K. and Mark M. Spiegel, (2011), "Cross-Country Causes and Consequences of the 2008 Crisis: An Update," European Economic Review, 55, 309-324.

Swanson, Eric T., (2011), "Let's Twist Again: A High-Frequency Event-Study Analysis of Operation Twist and Its Implications for QE2," Brookings Papers on Economic Activity, Spring, 151-207.

Yetman, James (2011a), "Exporting Recessions: International Links and the Business Cycle," Economics Letters, 110, 12-14.

Yetman, James (2011b), "The Decoupling of Asia-Pacific?," in Cheung and Ma, eds., Frontiers of Economics and Globalization, Volume 9, Chapter 10, 235-253.

Yetman, James and Lillie Lam, (2013), “Asia's Decoupling: Fact, Fairytale, or Forecast?,” forthcoming, Pacific Economic Review. 
Table 1: Business cycle correlations before and after crisis

\begin{tabular}{|c|c|c|}
\hline \multicolumn{3}{|c|}{ Business Cycle Correlations } \\
\hline & Before Crisis & After Crisis \\
\hline & 2002Q1-2007Q3 & 2009Q3-2012Q3 \\
\hline \multicolumn{3}{|c|}{ Correlation with Japan } \\
\hline Asia* & 0.807 & 0.713 \\
\hline China & 0.576 & 0.425 \\
\hline EU & 0.847 & 0.624 \\
\hline US & 0.875 & 0.818 \\
\hline ROW & 0.555 & 0.331 \\
\hline \multicolumn{3}{|c|}{ Correlation with China } \\
\hline Asia* & 0.705 & 0.665 \\
\hline EU & 0.714 & 0.812 \\
\hline US & 0.397 & 0.611 \\
\hline ROW & 0.672 & 0.411 \\
\hline \multicolumn{3}{|c|}{ Correlation with Asia* } \\
\hline EU & 0.912 & 0.765 \\
\hline US & 0.691 & 0.621 \\
\hline ROW & 0.537 & 0.390 \\
\hline
\end{tabular}

Asia includes Hong Kong, Indonesia, Korea, Malaysia, Philippines, Singapore, Thailand.

Correlations of 4-quarter growth rates in RGDP. All series are seasonally-adjusted and detrended using a Hodrick-Prescott filter. Growth for the Asia grouping is calculated as the average growth rate of the individual countries weighted by nominal GDP. 
Table 2: Regression results based on output gaps

\begin{tabular}{|lccccc|}
\hline \multicolumn{5}{c|}{ Regression: 8-quarter correlation on output gaps } \\
\hline \multirow{3}{*}{ Gap Partner } & $\underline{\text { Asia }}$ & $\underline{\text { China }}$ & $\underline{\text { Japan }}$ & Rest of Asia \\
& 0.0254 & 0.0058 & $0.0458^{* *}$ & $0.0726^{* * *}$ \\
Gap US & $(0.02)$ & $(0.02)$ & $(0.02)$ & $(0.03)$ \\
& $-0.0723^{* * *}$ & $-0.0829^{* * *}$ & $-0.0738^{* * *}$ & $-0.0546^{* * *}$ \\
Constant & $(0.01)$ & $(0.01)$ & $(0.02)$ & $(0.02)$ \\
& $0.4118^{* * *}$ & $0.2360^{* *}$ & $0.4840^{* * *}$ & $0.2894^{* * *}$ \\
& $(0.07)$ & $(0.09)$ & $(0.05)$ & $(0.08)$ \\
Obs & & & & \\
R2 & 55 & 55 & 55 & 55 \\
\hline
\end{tabular}

Regression of US RGDP correlation with various partner countries using output gaps.

Sample: 1999Q1-2012Q3

Table 3: Regression results based on unemployment gaps

\begin{tabular}{|lccc|}
\hline \multicolumn{4}{|c|}{ Regression: 8-quarter correlation on unemployment gaps } \\
\hline \multirow{3}{*}{ Unemployment Gap Partner } & \begin{tabular}{l} 
Japan \& Korea \\
\cline { 2 - 4 }
\end{tabular} & $\frac{\text { Japan }}{}$ & Korea \\
Unemployment Gap US & $(0.10)$ & $-0.15^{* *}$ & $-0.20^{* * *}$ \\
& $0.10^{* * *}$ & $0.12^{* * *}$ & 0.05 \\
Constant & $(0.02)$ & $(0.02)$ & $(0.03)$ \\
& $0.67^{* * *}$ & $0.62^{* * *}$ & $0.40^{* * *}$ \\
& $(0.03)$ & $(0.04)$ & $(0.07)$ \\
Obs & & & \\
R2 & 55 & 55 & 55 \\
\hline
\end{tabular}

Regression of US RGDP correlation with various partner countries using unemployment gaps.

Sample: 1999Q1-2012Q3

Table 4: Comparing regression results

\begin{tabular}{|c|c|c|c|c|c|c|c|}
\hline \multirow[b]{2}{*}{ Country } & \multicolumn{4}{|c|}{ Output Gap Regressions } & \multicolumn{3}{|c|}{ Unemployment Gap Regressions } \\
\hline & Asia & China & Japan & Rest of Asia & Japan \& Korea & Japan & Korea \\
\hline $\mathrm{R} 2$ in sample & 0.37 & 0.46 & 0.47 & 0.25 & 0.43 & 0.40 & 0.17 \\
\hline RMSE out-of-sample & 0.43 & 0.3 & 0.29 & 0.42 & 0.3 & 0.31 & 0.47 \\
\hline Obs & 47 & 47 & 47 & 47 & 47 & 47 & 47 \\
\hline
\end{tabular}

Asia consists of Korea and Indonesia in the output gap regression results.

Sample: 1999Q1-2010Q3

Forecast: 2010Q4-2012Q3 
Table 5: Business Cycle Correlations between the US and Asia

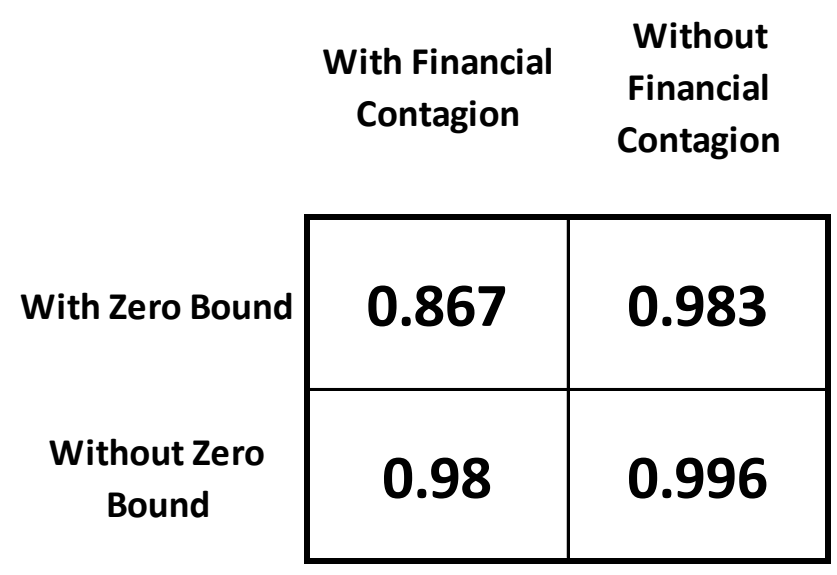

Business cycle correlation coefficient of US and Asia blocks between shock and steady state. Financial contagion case implies identical spreads shocks for all blocks. No financial contagion corresponds to a corporate spread shock for the Europe block only. Zero bound implies that the US and Europe at the zero bound constraint. No zero bound implies monetary policy is unconstrained for all blocks. 
Figure 1: GDP Growth for Groupings

\section{Real GDP Growth}

4 quarter percent change

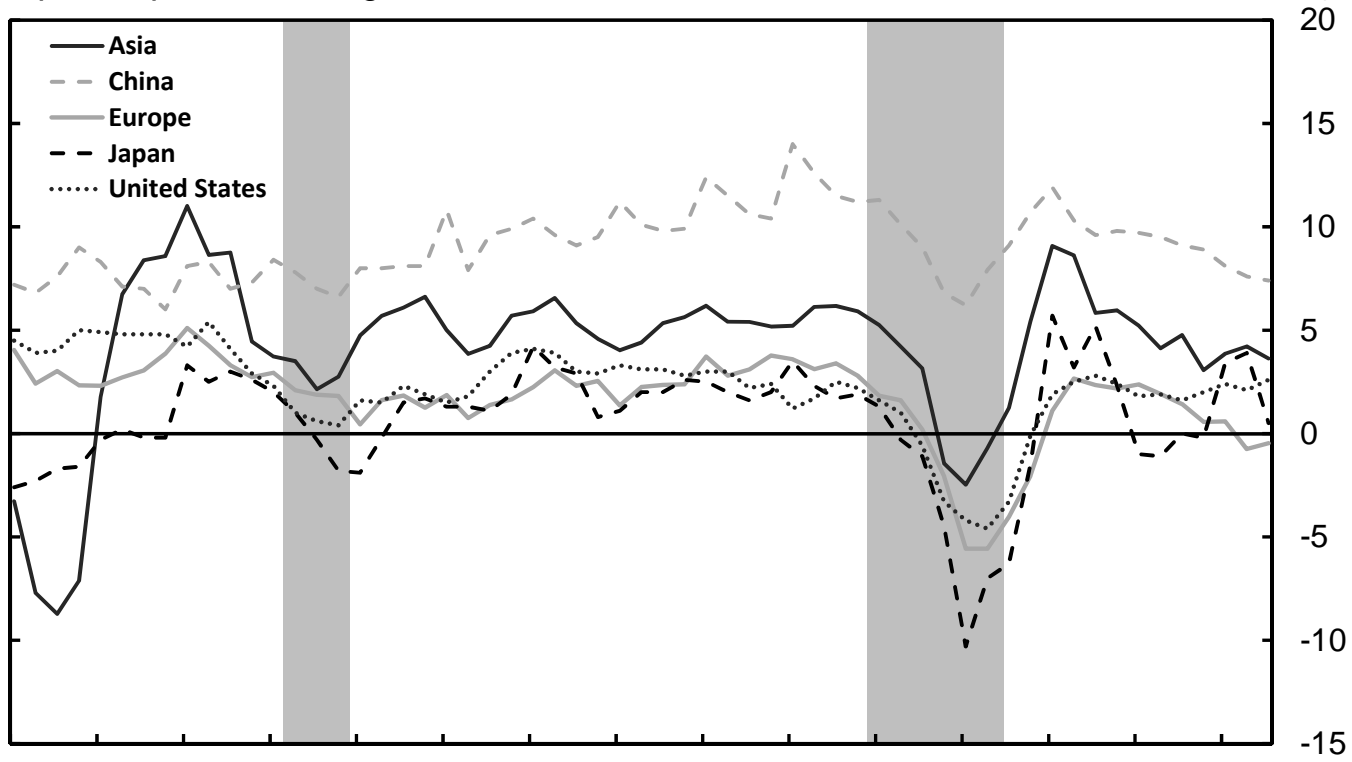

199819992000200120022003200420052006200720082009201020112012

Asia: Weighted average of Korea, Hong Kong, Indonesia, Malaysia, Philippines, Singapore, Thailand

Figure 2: Business cycle correlations with the US

\section{Business Cycle Correlations with the U.S.}

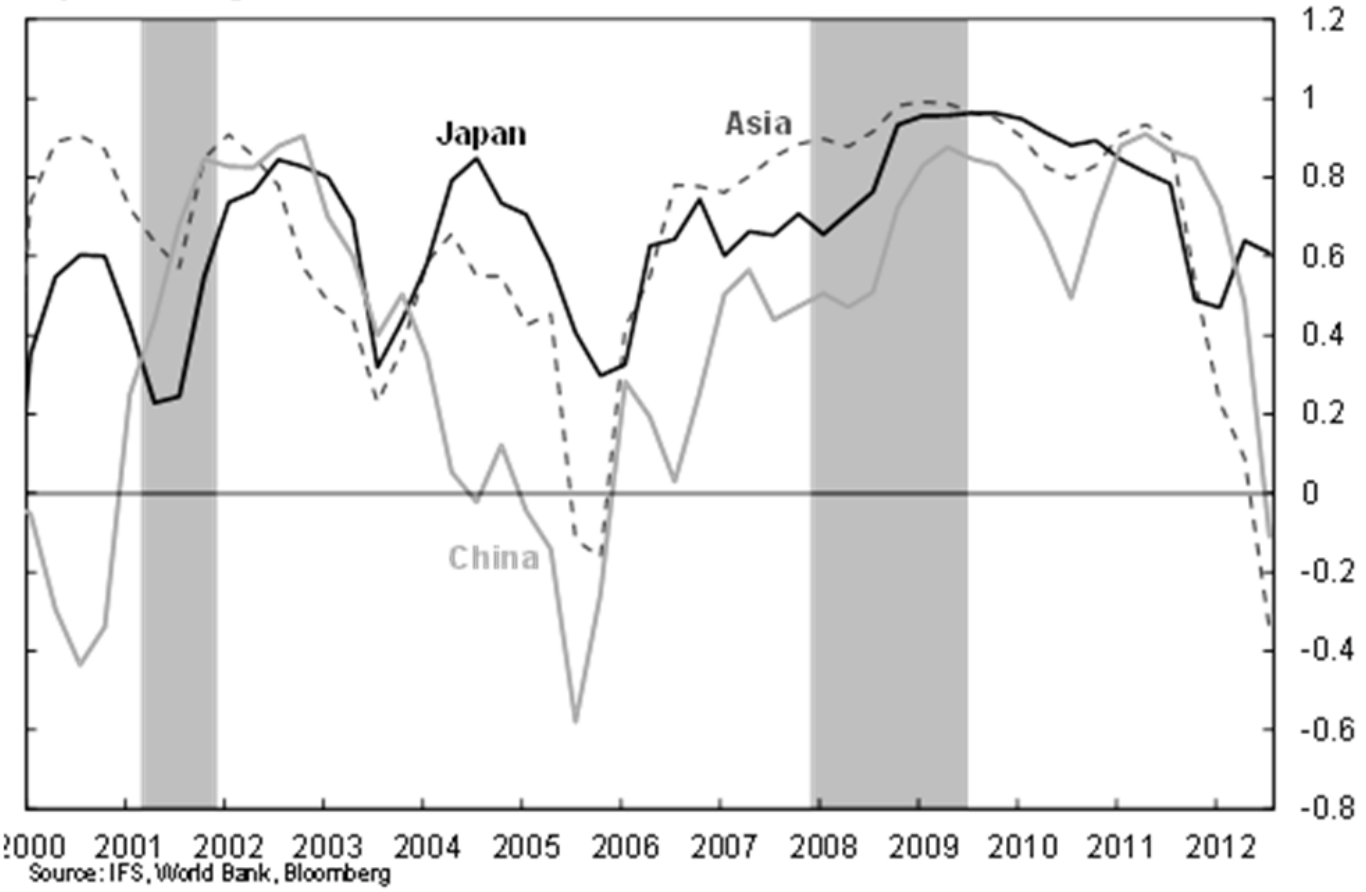


Figure 3a: Predictions using and output gaps

\section{Predicting business cycle correlation using output gaps}

Asia

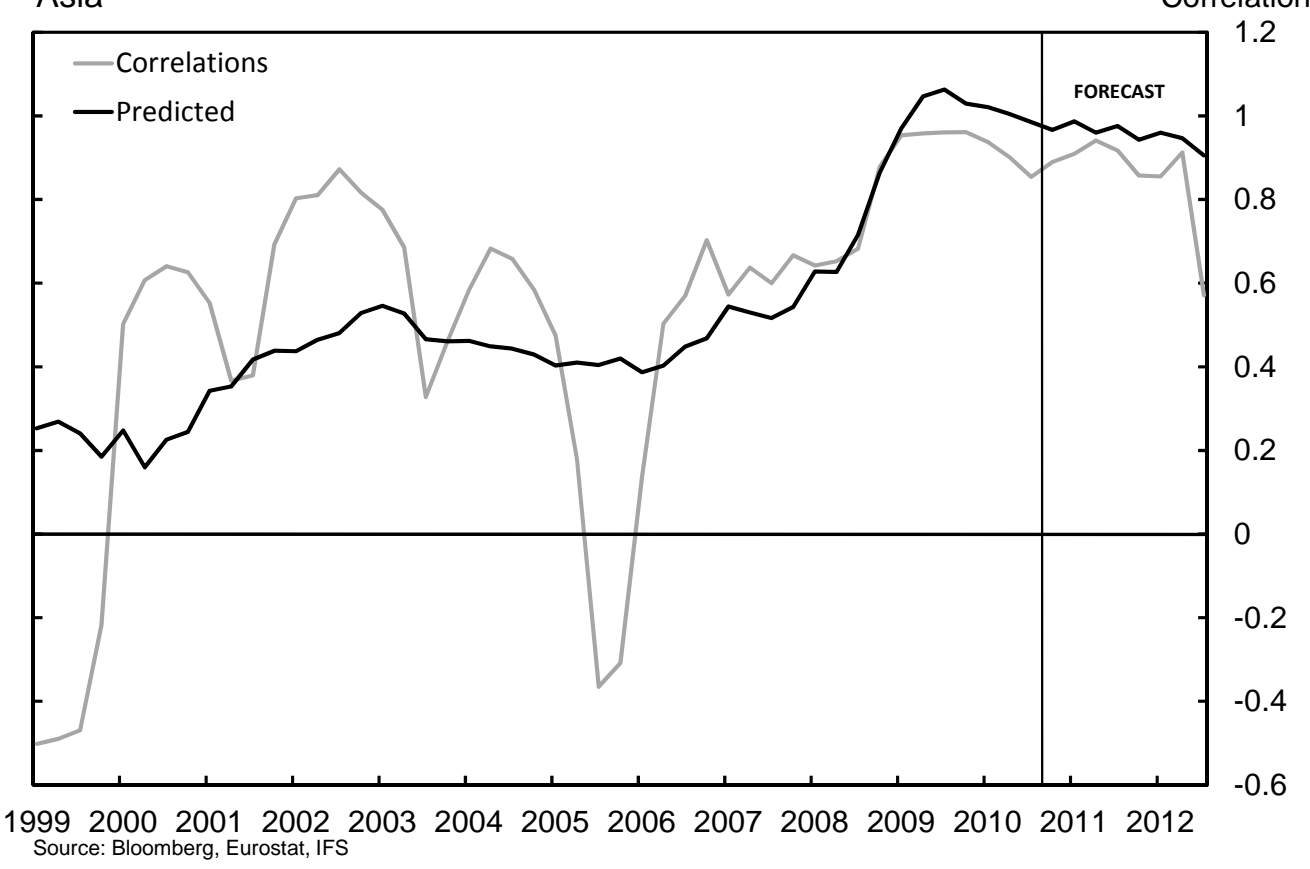

Forecast values using estimates fitted over 1999Q1-2010Q3. Forecast includes 2010Q4-2012Q4.

Figure 3b: Predictions Using Unemployment Gaps

\section{Predicting business cycle correlation using unemployment gaps}

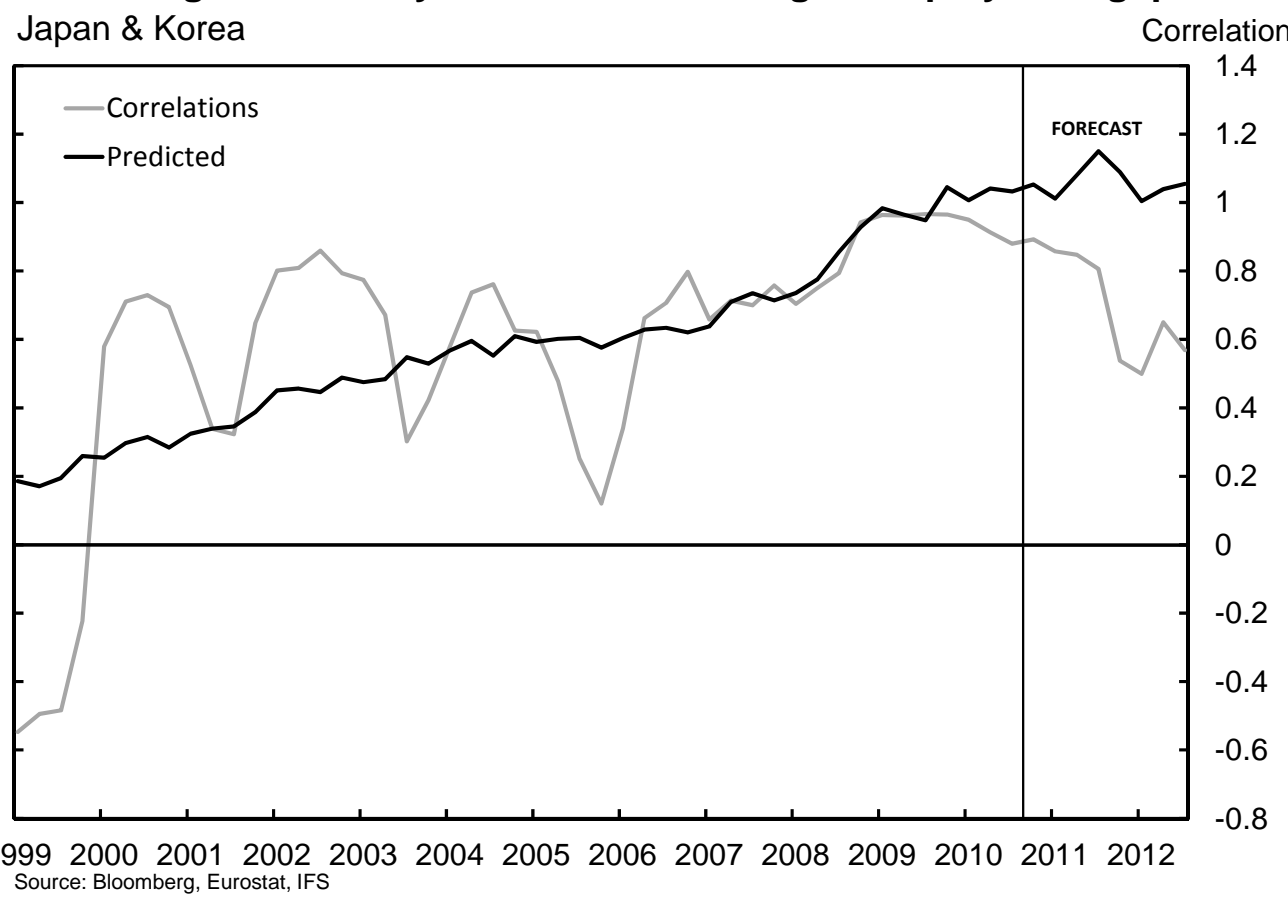

Forecast values using estimates fitted over 1999Q1-2010Q3. Forecast includes 2010Q4-2012Q4. 
Figure 4: Predicting using cyclical positions and output gaps (components)

Predicting business cycle correlation using output gaps China

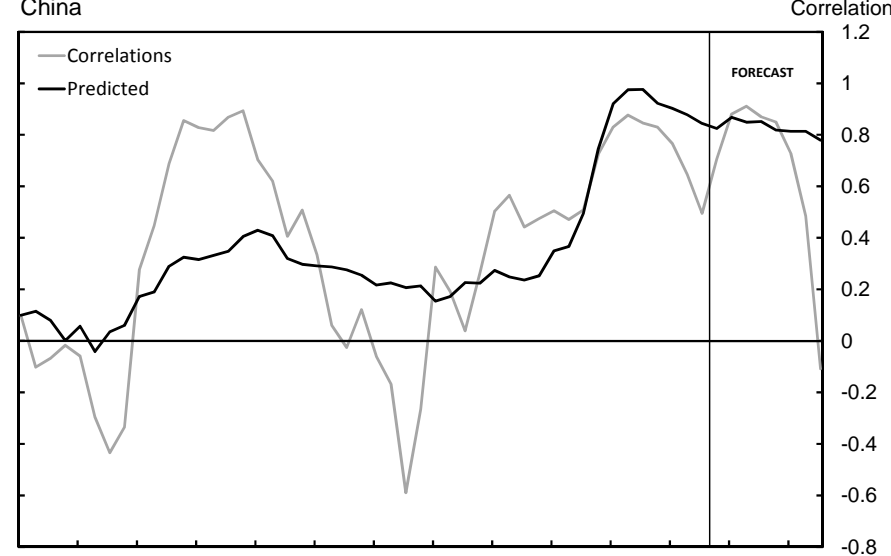

199922000200120022003200420052006200720082009201020112012
Source: Bloomberg, Eurostat, IFS

Predicting business cycle correlation using unemployment gaps Japan

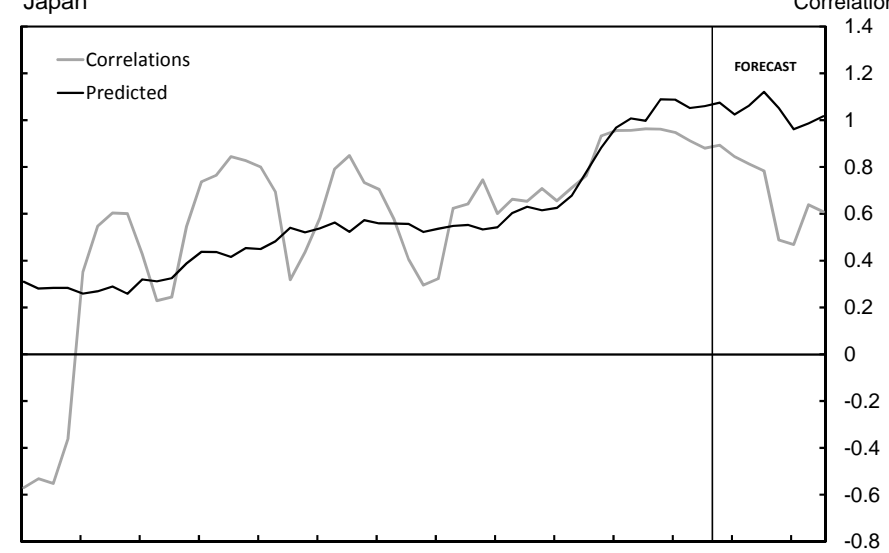

19992000200120022003200420052006200720082009201020112012 Source: Bloomberg, Eurostat, IFS

Predicting business cycle correlation using unemployment gaps Japan \& Korea

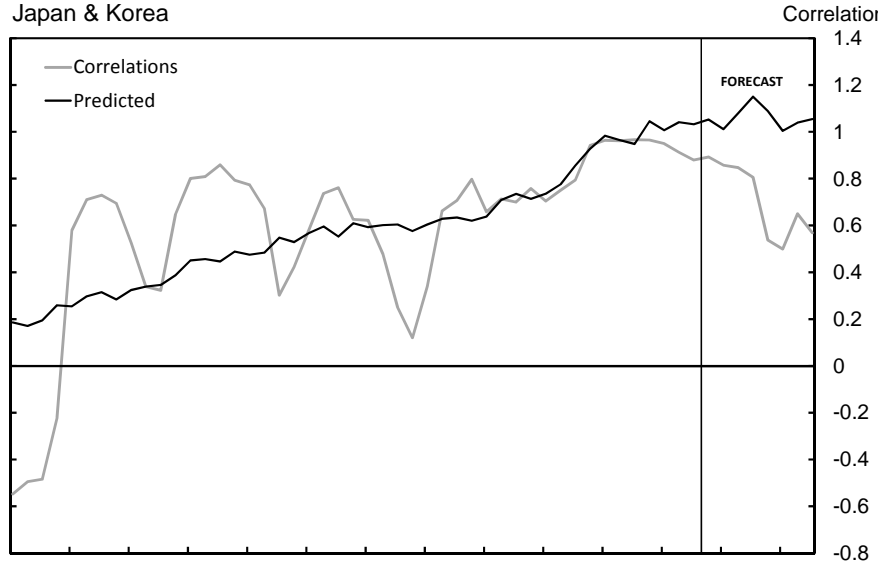

19992000200120022003200420052006200720082009201020112012 Forecast values using estimates fitted over 1999Q1-2010Q3. Forecast includes 2010Q4-2012Q4.

Predicting business cycle correlation using output gaps Japan Source: Bloomberg, Eurostat, IFS

Predicting business cycle correlation using output gaps Rest of Asia : Korea \& Indonesia

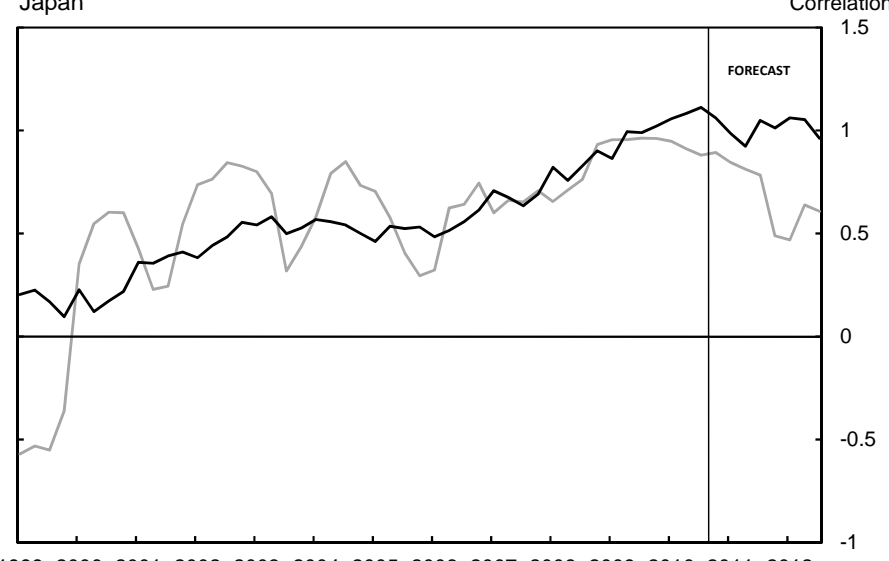

19992000200120022003200420052006200720082009201020112012

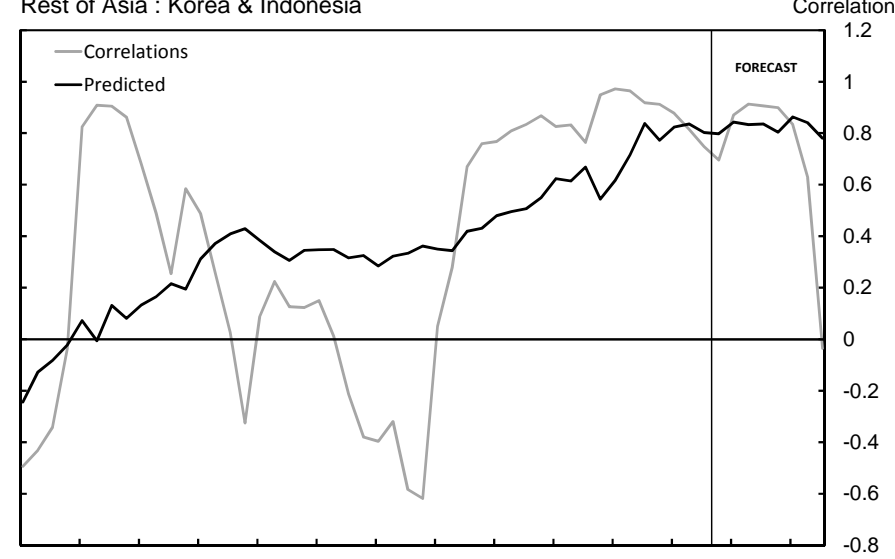

19992000200120022003200420052006200720082009201020112012 
Figure 5: Benchmark impulse responses to an increase in European corporate bond spreads
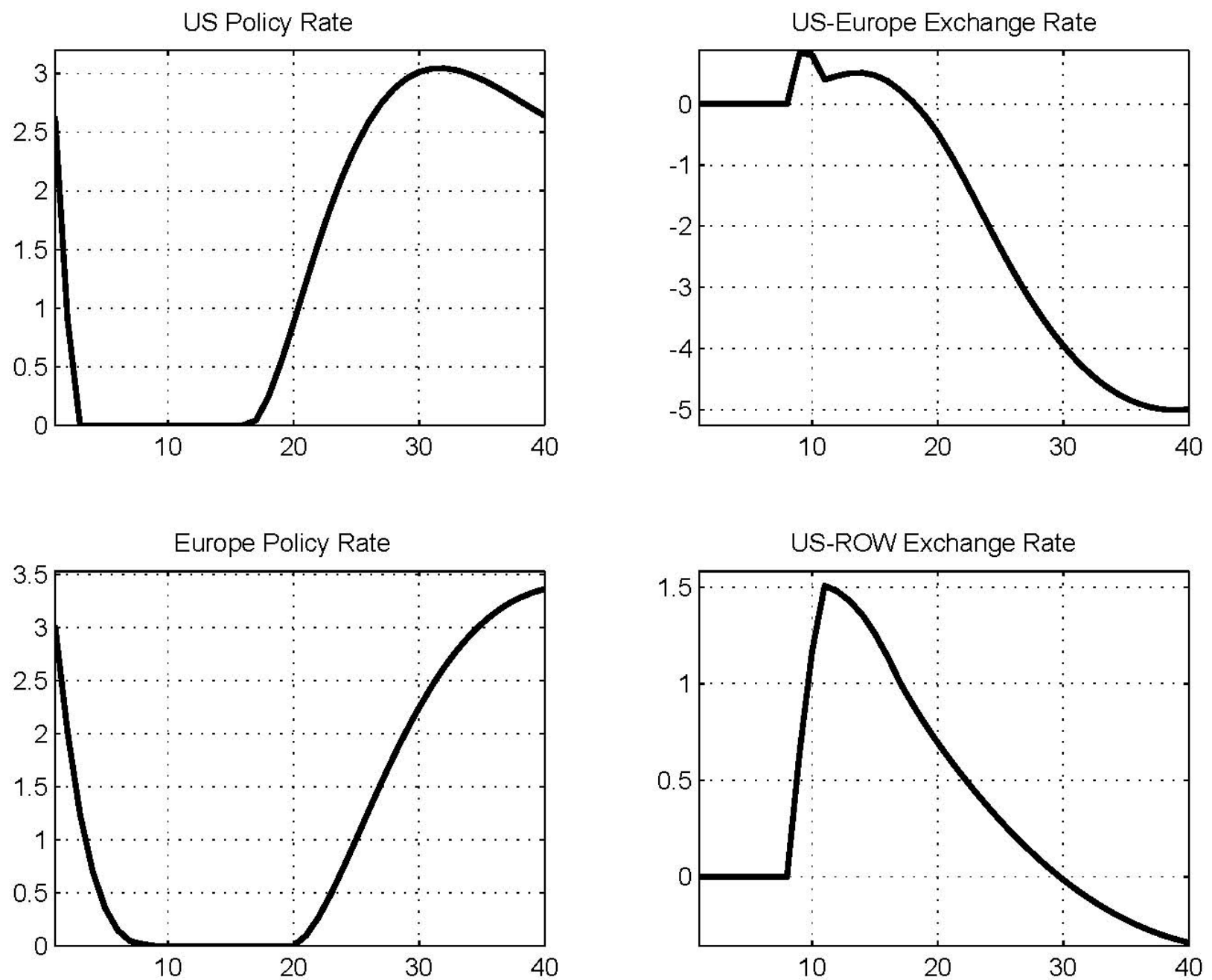

Impulse responses from simulation based European spreads increased by 500 basis points. Negative aggregate demand shock at time zero, adverse European spread shock at time 8 . $x$ axis reflects quarters after the aggregate demand shock. $y$ axis reflects percentage distances from the steady state. 
Figure 6: Responses of GDP and corporate spreads to an increase in European corporate bond spreads
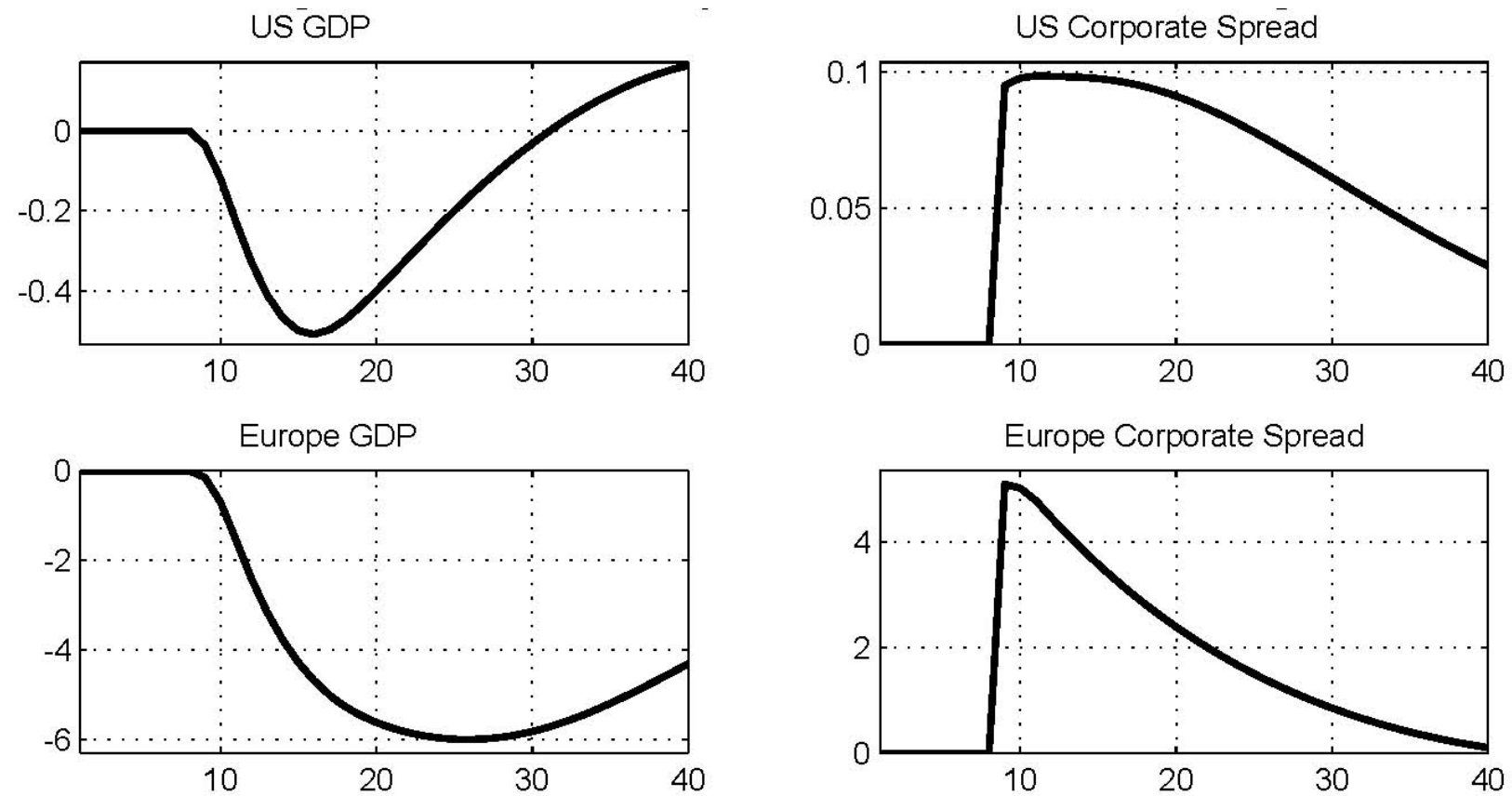

Asia GDP

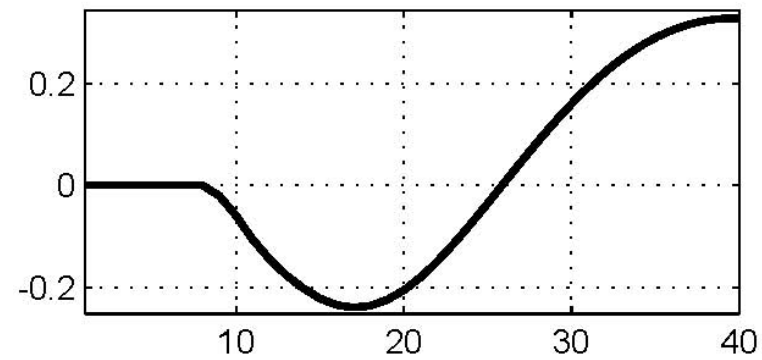

Asia Corporate Spread

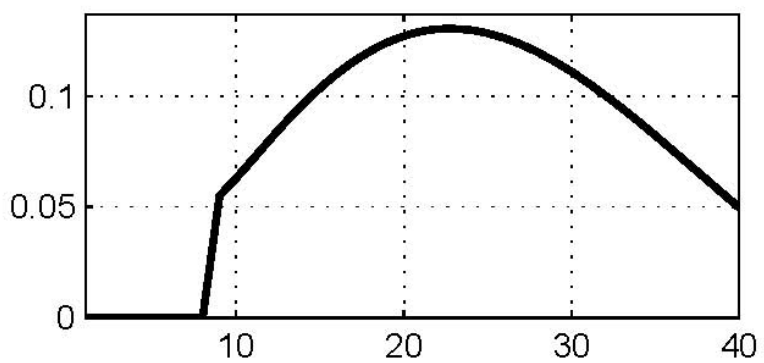

Impulse responses from simulation based European spreads increased by 500 basis points. Negative aggregate demand shock at time zero, adverse European spread shock at time 8 . $x$ axis reflects quarters after the aggregate demand shock. $y$ axis reflects percentage distances from the steady state. 
Figure 7: Peak effect on GDP from a financial shock originating in Europe with zero lower bound constraint

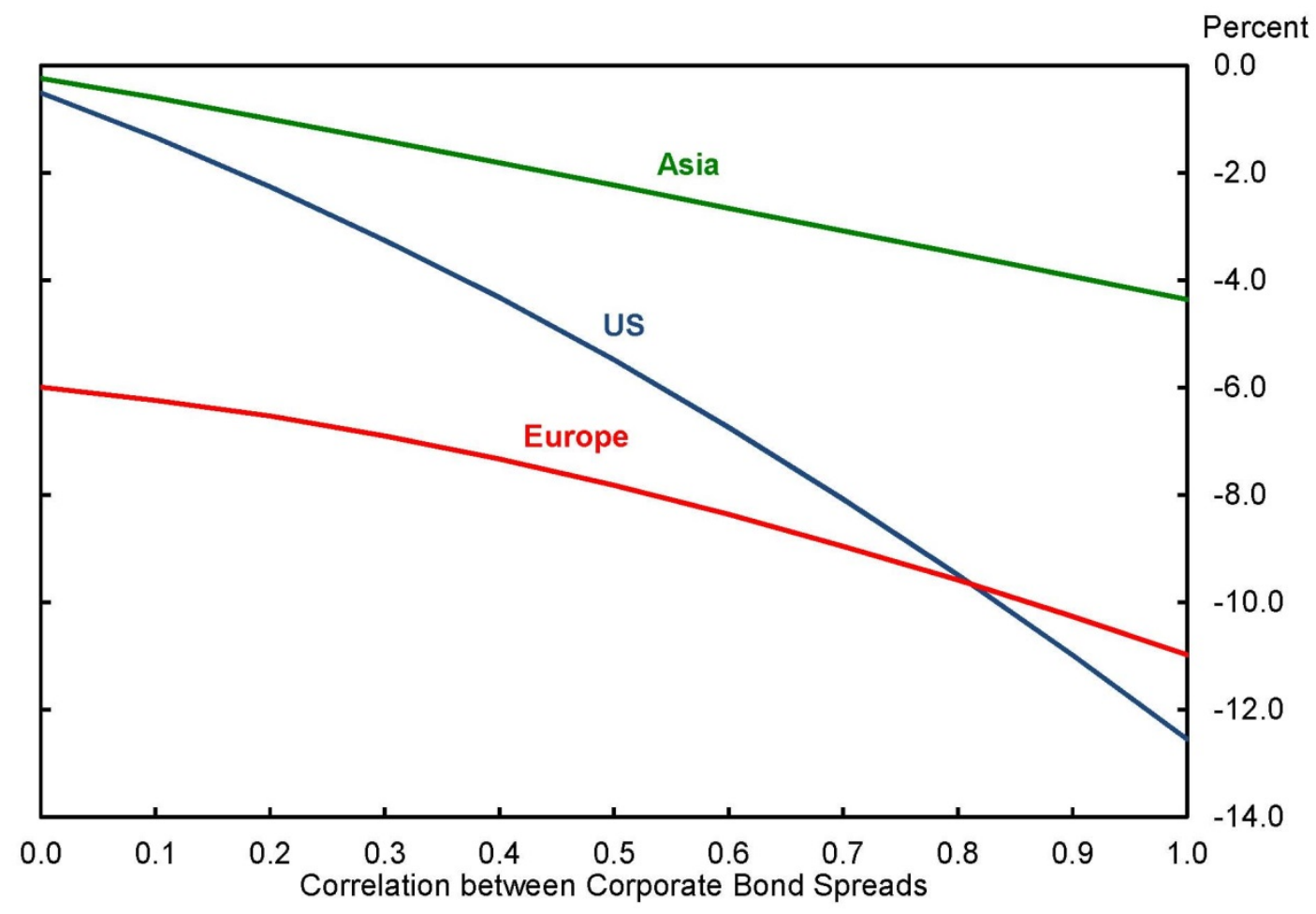

Peak percentage deviation from steady state following 500 basis point increase in European spreads and increased US and Asia block spreads. US and European monetary policies constrained by zero bound. Negative aggregate demand shock at time zero, adverse European, US, and Asia block spread shocks at time 8. $x$ axis reflects correlation between European spread shock and those in US and Asia block. y axis reflects peak percentage distances from the steady state. 
Figure 8: Peak effect on GDP from a financial shock originating in Europe without zero lower bound constraint

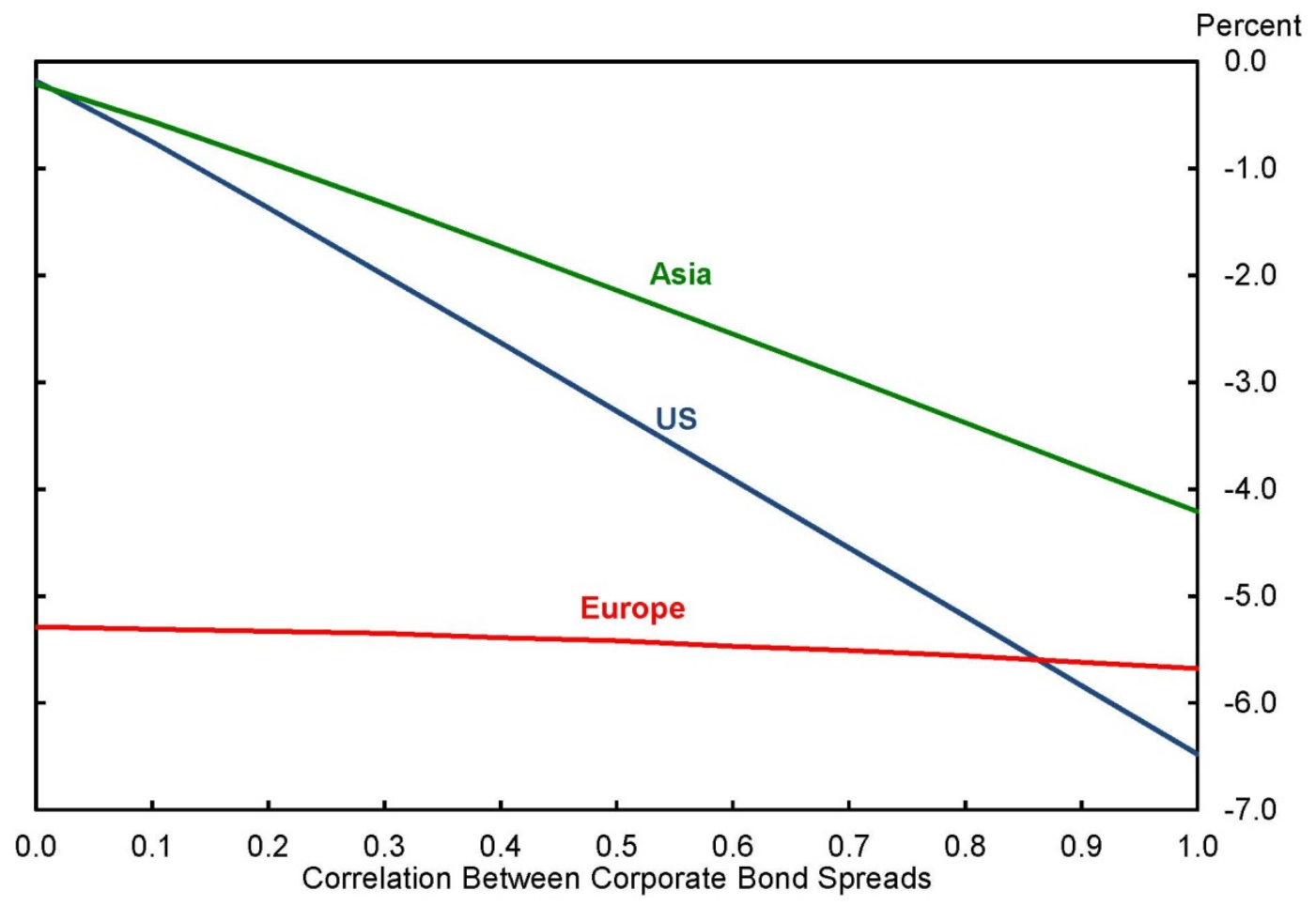

Peak percentage deviation from steady state following 500 basis point increase in European spreads and increased US and Asia block spreads. No zero bound constraint on monetary policy. Negative aggregate demand shock at time zero, adverse European, US, and Asia block spread shocks at time $8 . x$ axis reflects correlation between European spread shock and those in US and Asia block. y axis reflects peak percentage distances from the steady state. 
Appendix 1: Regression results from output gap predictions

\begin{tabular}{|lccccc|}
\hline \multicolumn{5}{c|}{ Regression: 8-quarter correlation on output gaps } \\
\hline \multirow{4}{*}{ Gap Partner } & $\underline{\text { Asia }}$ & $\underline{\text { China }}$ & $\underline{\text { Japan }}$ & Rest of Asia \\
& 0.0265 & 0.0029 & $0.0539^{* * *}$ & $0.0761^{* * *}$ \\
Gap US & $(0.02)$ & $(0.02)$ & $(0.02)$ & $(0.03)$ \\
& $-0.0778^{* * *}$ & $-0.0925^{* * *}$ & $-0.0946^{* * *}$ & $-0.0597^{* * *}$ \\
Constant & $(0.01)$ & $(0.01)$ & $(0.02)$ & $(0.02)$ \\
& $0.4153^{* * *}$ & $0.2517^{* * *}$ & $0.4999^{* * *}$ & $0.2950^{* * *}$ \\
& $(0.07)$ & $(0.09)$ & $(0.05)$ & $(0.08)$ \\
Obs & & & & \\
R2 & 47 & 47 & 47 & 47 \\
\hline
\end{tabular}

In-sample regression results for the forecasting procedure presented in table 4. Sample: 1999Q1-2010Q3

Appendix 2: Regression results from unemployment gap predictions

\begin{tabular}{|lccc|}
\hline \multicolumn{4}{c|}{ Regression: 8-quarter correlation on unemployment gaps } \\
\cline { 1 - 5 } & Japan \& Korea & Japan & Korea \\
\cline { 2 - 5 } Unemployment Gap Partner & $-0.331^{* * *}$ & $-0.229^{* * *}$ & $-0.223^{* * *}$ \\
& $(0.11)$ & $(0.08)$ & $(0.06)$ \\
Unemployment Gap US & $0.133^{* * *}$ & $0.153^{* * *}$ & $0.0629^{*}$ \\
& $(0.02)$ & $(0.03)$ & $(0.03)$ \\
Constant & $0.744^{* * *}$ & $0.695^{* * *}$ & $0.423^{* * *}$ \\
& $(0.03)$ & $(0.03)$ & $(0.07)$ \\
& & & \\
Obs & 47 & 47 & 47 \\
R2 & 0.432 & 0.396 & 0.169 \\
\hline
\end{tabular}

In-sample regression results for the forecasting procedure presented in table 4 .

Sample: 1999Q1-2010Q3 